\title{
The global histone modification pattern correlates with overall survival in metachronous liver metastasis of colorectal cancer
}

\author{
HIROSHI TAMAGAWA ${ }^{1}$, TAKASHI OSHIMA ${ }^{4}$, MANABU SHIOZAWA ${ }^{1}$, SOICHIRO MORINAGA ${ }^{1}$, \\ YOSHIYASU NAKAMURA ${ }^{3}$, MITSUYO YOSHIHARA ${ }^{3}$, YUJI SAKUMA ${ }^{3}$, YOICHI KAMEDA ${ }^{2}$, \\ MAKOTO AKAIKE $^{1}$, MUNETAKA MASUDA $^{5}$, TOSHIO IMADA $^{5}$ and YOHEI MIYAGI ${ }^{3}$ \\ Departments of ${ }^{1}$ Gastrointestinal Surgery and ${ }^{2}$ Pathology, Kanagawa Cancer Center, and ${ }^{3}$ Division of \\ Molecular Pathology and Genetics, Kanagawa Cancer Center Research Institute, Yokohama 241-0815; \\ ${ }^{4}$ Gastrointestinal Center, Yokohama City University Medical Center, Yokohama 232-0024; \\ ${ }^{5}$ Department of Surgery, Yokohama City University, Yokohama 236-0004, Japan
}

Received September 12, 2011; Accepted October 21, 2011

DOI: $10.3892 /$ or.2011.1547

\begin{abstract}
Post-translational histone modifications are known to be altered in cancer tissues, and differences in the histone modification levels have recently been used to predict the clinical outcome in patients with certain types of cancer. In this study, we evaluated the immunohistochemical staining patterns of histone $\mathrm{H} 3$ dimethylation and acetylation in metachronous liver metastasis of colorectal carcinomas and examined its correlation with patient prognosis. Double $2 \mathrm{~mm}$ core tissue microarrays were made from 54 paraffin-embedded samples of liver metastasis from colorectal adenocarcinoma, and were examined by an immunohistochemical analysis of histone $\mathrm{H} 3$ lysine 4 (H3K4) dimethylation, histone, H3 lysine 9 (H3K9) dimethylation and histone H3 lysine 9 (H3K9) acetylation. Positive tumor cell staining for each histone modification was used to classify patients into low- and highstaining groups, which were then examined for correlations with the clinicopathological parameters and clinical outcome. Dimethylation of H3K4 correlated with the tumor histological type $(\mathrm{P}=0.043)$, and acetylation of $\mathrm{H} 3 \mathrm{~K} 9$ correlated with the tumor histological type $(\mathrm{P}=0.016)$. In addition, lower levels of $\mathrm{H} 3 \mathrm{~K} 4$ dimethylation correlated with a poor survival rate $(\mathrm{P}=0.035)$. The multivariate survival analysis showed that the $\mathrm{H} 3 \mathrm{~K} 4$ dimethylation status is an independent prognostic factor for colorectal cancer patients $(\mathrm{P}=0.011)$. We suggest that the pattern of histone modification as detected by immunohistochemistry may be an independent prognostic factor for metachronous liver metastasis of colorectal carcinomas.
\end{abstract}

Correspondence to: Dr Hiroshi Tamagawa, Department of Gastrointestinal Surgery, Kanagawa Cancer Center, 1-1-2 Nakao, Asahi-ku, Yokohama 241-0815, Japan

E-mail: tamagawah@kcch.jp

Key words: histone modification, prognostic factor, immunohistochemistry, liver metastasis, H3K4, H3K9, colorectal cancer

\section{Introduction}

Colorectal cancer (CRC) is the third most common cancer and the fourth leading cause of cancer-related deaths worldwide (1). In spite of progress made in CRC chemotherapy, the outcomes of $\mathrm{CRC}$ with distant metastasis still remain poor. Liver metastasis of CRC is an important prognostic factor, and occurs in $20-25 \%$ of CRC patients (2). Hepatic resection is a potentially curative therapy for colorectal liver metastases. However, recurrence develops in approximately $60-70 \%$ of all such patients after hepatectomy, thus, suggesting that patients with colorectal liver metastasis often do not benefit from hepatectomy. In addition, the prognostic factors for survival that can be obtained from the resected specimens and the mechanism of tumor progression of the metastases have not yet been fully elucidated. Therefore, it is important to identify the specific biomarker of CRC outcomes, especially for patients with liver metastases.

DNA methylation and histone modification are major epigenetic mechanisms controlling gene regulation, and they are frequently altered in cancer (3). Changes in DNA methylation are closely related to patterns of histone modification (4). Cellular patterns of histone modifications have been reported as providing independent prognostic information for several cancers, including prostate $(5,6)$, kidney $(6)$, lung (6-8), gastric (9), ovarian $(10)$, pancreatic $(10,11)$, esophageal $(12,13)$ and breast cancers $(10,14)$. Modification of histones by methylation and acetylation at lysine residues is generally associated with gene inactivation or silencing (15-19). In CRC patients, it has also been previously reported that reduced $\mathrm{H} 3$ lysine 4 methylation and increased $\mathrm{H} 3$ lysine 9 methylation play a critical role in the maintenance of promoter DNA methylationassociated gene silencing (15). However, to date, there have been no reports on the prognostic significance of global histone modifications in cases of CRC, including liver metastasis.

In this study, we classified the expression levels of the histone dimethylation in 54 pairs of the liver metastases obtained from patients with metachronous liver metastasis of CRC. To evaluate the clinical significance of histone modification, 

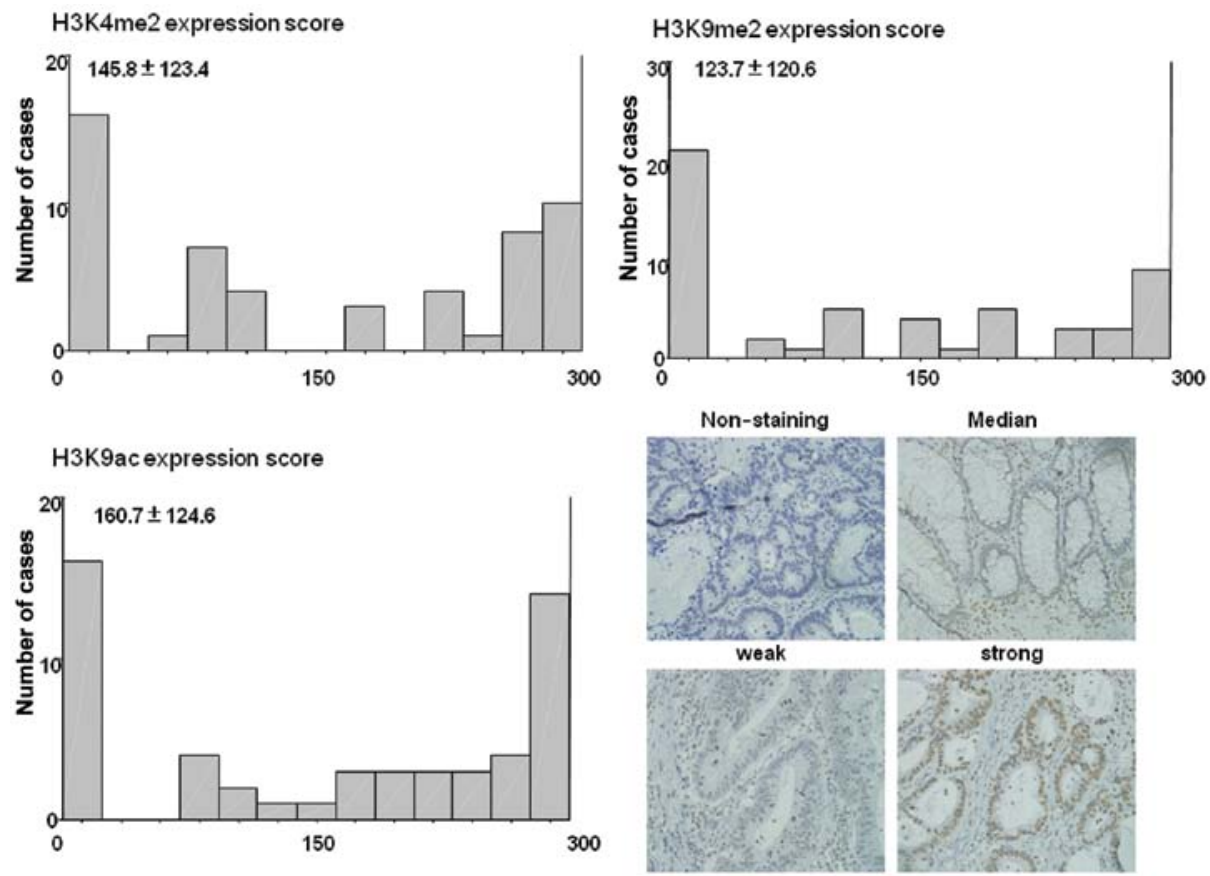

Figure 1. Histograms depicting the detection of histone modifications in CRC by immunohistochemistry. Representative examples of CRC or liver metastasis tissue cores presenting with 4 levels of staining (non-staining, weak, median and strong) of the following histone modifications: H3K4me2, H3K9me2 and H3K9ac. Original magnification, x200. Histograms showing the distribution of $\mathrm{H}$-scores plotted against the number of cases for the histone modifications.

we examined the correlation between the relative expression of global histone modification patterns and the outcomes in patients with CRC.

\section{Materials and methods}

Patients and samples. We retrospectively studied the surgical specimens of liver metastasis obtained from 54 patients with metachronous liver metastasis of CRC. All of the patients had undergone curative radical (R0) resection for primary colorectal adenocarcinoma, and none of them were observed to have liver metastasis at the first operation. The metachronous liver metastases were subjected to curative radical resection at a later time. The patients underwent surgery at Kanagawa Cancer Center between January 1992 and December 2007. Primary colorectal tumors and the corresponding liver metastases were obtained from each patient. Informed consent was obtained from each patient. In all cases, archival hematoxylin and eosin-stained $(\mathrm{H} \& \mathrm{E})$ slides of the respective liver metastasis specimens were retrieved and reviewed to confirm the pathological features, as well as to select suitable tissue blocks for immunohistochemical analysis. The Ethics Committees of the Kanagawa Cancer Center approved the protocol before initiation of the study. No patient had any other malignancies.

Tissue microarrays and immunohistochemistry. Microarrays consisting of cores, each $2 \mathrm{~mm}$ in diameter, were prepared from formalin-fixed paraffin-embedded tissue blocks of surgically removed liver metastases, and one tissue core from each liver metastasis that consisted of $>80 \%$ carcinoma cells was prepared for analysis.

Immunohistochemical staining was performed using commercially-available polyclonal rabbit anti-histone anti- bodies raised against dimethyl-histone $\mathrm{H} 3$ lysine4 (H3K4me2), dimethyl-histone $\mathrm{H} 3$ lysine9 (H3K9me2) and acetyl-histone H3 lysine9 (H3K9ac) (Cell Signaling Technology Inc., Danvers, MA). Tissue microarray blocks were sectioned at a thickness of $4 \mu \mathrm{m}$ and mounted on pre-coated glass slides. The sections were de-paraffinized through a graded series of xylene and rehydrated through a graded series of alcohol to distilled water. Endogenous peroxidase was quenched with $3 \%$ hydrogen peroxide in methanol at room temperature. The sections were placed in a $95^{\circ} \mathrm{C}$ solution of $0.01 \mathrm{M}$ sodium citrate buffer ( $\mathrm{pH}$ 6.0) for $40 \mathrm{~min}$ for antigen retrieval. Normal goat serum (5\%) was then applied for 15 min to block non-specific protein binding sites. Primary rabbit anti-histone polyclonal antibodies were applied for $1 \mathrm{~h}$ at room temperature at the following dilutions: anti-H3K4me2 at 1:300, anti-H3K9me2 at 1:300 and anti-H3K9ac at 1:300. Immunoreactive proteins were detected using the Simple Stain MAX PO (R).

All sections were counterstained with Mayer's hematoxylin, and negative controls were included in each staining sequence. The intensity and global level of staining were scored semi-quantitatively for each tissue microarray by an investigator blinded to all of the clinicopathological variables. The global level of staining refers to the percentage of tumor cells that stained positively for an antibody within each tissue microarray at x200 magnification using a light microscope.

Scoring of immunohistochemical reactivity. Immunohistochemical scoring was done by the modified Histo-score (H-score) (20), which involves semi-quantitative assessment of both the intensity of staining (graded as 0 , no staining; 1 , weak; 2 , median; and 3, strong, using adjacent normal mucosa as the median) and the percentage of positive cells. The range 
Table I. Relationship between the expression of the histone modifications and the clinicopathological features.

\begin{tabular}{|c|c|c|c|c|c|c|c|c|c|}
\hline \multirow[b]{2}{*}{ Variables/categories } & \multicolumn{2}{|c|}{$\begin{array}{l}\mathrm{H} 3 \mathrm{~K} 4 \mathrm{me} 2 \\
\text { expression }\end{array}$} & \multirow[b]{2}{*}{ P-value } & \multicolumn{2}{|c|}{$\begin{array}{l}\mathrm{H} 3 \mathrm{~K} 9 \mathrm{me} 2 \\
\text { expression }\end{array}$} & \multirow[b]{2}{*}{ P-value } & \multicolumn{2}{|c|}{$\begin{array}{l}\mathrm{H} 3 \mathrm{~K} 9 \mathrm{ac} \\
\text { expression }\end{array}$} & \multirow[b]{2}{*}{ P-value } \\
\hline & $\begin{array}{l}\text { Low } \\
(\mathrm{n}=28)\end{array}$ & $\begin{array}{l}\text { High } \\
(\mathrm{n}=26)\end{array}$ & & $\begin{array}{l}\text { Low } \\
(\mathrm{n}=30)\end{array}$ & $\begin{array}{l}\text { High } \\
(\mathrm{n}=24)\end{array}$ & & $\begin{array}{c}\text { Low } \\
(\mathrm{n}=23)\end{array}$ & $\begin{array}{l}\text { High } \\
(\mathrm{n}=31)\end{array}$ & \\
\hline Age & $61 \pm 9$ & $62 \pm 9$ & $0.892^{\mathrm{b}}$ & $59 \pm 7$ & $64 . \pm 11$ & $0.075^{\mathrm{b}}$ & $61 \pm 7$ & $62 \pm 10$ & $0.517^{\mathrm{b}}$ \\
\hline Gender & & & $0.535^{\mathrm{c}}$ & & & $0.015^{\mathrm{c}}$ & & & $0.975^{\mathrm{c}}$ \\
\hline Male & 16 & 17 & & 14 & 19 & & 14 & 19 & \\
\hline Female & 12 & 9 & & 16 & 5 & & 9 & 12 & \\
\hline Size $(\mathrm{cm})$ & & & $0.554^{\mathrm{c}}$ & & & $0.902^{\mathrm{c}}$ & & & $0.22^{\mathrm{c}}$ \\
\hline$<5$ & 15 & 16 & & 17 & 14 & & 11 & 20 & \\
\hline$\geq 5$ & 13 & 10 & & 13 & 10 & & 12 & 11 & \\
\hline Histological type $\mathrm{a}^{\mathrm{a}}$ & & & $\mathbf{0 . 0 4 3}^{\mathrm{c}}$ & & & $0.063^{\mathrm{c}}$ & & & $0.016^{c}$ \\
\hline Well/Moderate & 24 & 26 & & 26 & 24 & & 19 & 31 & \\
\hline Poor/Mucinous & 4 & 0 & & 4 & 0 & & 4 & 0 & \\
\hline Depth of invasion & & & $0.777^{\mathrm{c}}$ & & & $0.429^{c}$ & & & $0.554^{\mathrm{c}}$ \\
\hline $\mathrm{T} 1-\mathrm{T} 3$ & 14 & 12 & & 13 & 13 & & 10 & 16 & \\
\hline $\mathrm{T} 4$ & 14 & 14 & & 17 & 11 & & 13 & 15 & \\
\hline Location & & & $0.151^{\mathrm{c}}$ & & & $0.322^{\mathrm{c}}$ & & & $0.724^{c}$ \\
\hline Colon & 14 & 18 & & 16 & 16 & & 13 & 19 & \\
\hline Rectum & 14 & 8 & & 14 & 8 & & 10 & 12 & \\
\hline Lymph node metastasis & & & $0.171^{\mathrm{c}}$ & & & $0.257^{\mathrm{c}}$ & & & $0.623^{\mathrm{c}}$ \\
\hline Absent & 6 & 10 & & 7 & 9 & & 6 & 10 & \\
\hline Present & 22 & 16 & & 23 & 15 & & 17 & 21 & \\
\hline Adjuvant chemotherapy & & & $0.394^{\mathrm{c}}$ & & & $0.066^{\mathrm{c}}$ & & & $0.902^{c}$ \\
\hline Absent & 14 & 10 & & 10 & 14 & & 10 & 14 & \\
\hline Present & 14 & 16 & & 20 & 10 & & 13 & 17 & \\
\hline
\end{tabular}

${ }^{a}$ Well, well differentiated; moderate, moderately differentiated; Poor, poorly differentiated. ${ }^{b}$ Wilcoxon test; ${ }^{\text {cPearson's }} \chi^{2}$ test. Bold indicates values that were statistically significant $(<0.05)$.

of possible scores is 0-300, enabling us to categorize our cases into biologically relevant groups depending on different levels of detection, which could potentially be missed using simpler scoring methods. Tumor samples with an H-score $<150$ for individual chromatin markers were designated as having low detection, where scores $\geq 150$ were designated as high detection. The distribution of staining was assessed in tissue microarray sections.

Statistical analysis. The relationship between histone modification scores and potential explanatory variables, including age, gender, tumor size, histological type, depth of invasion, lymph node metastasis, adjuvant chemotherapy and location were evaluated with the $\chi^{2}$ test and the Wilcoxon test. The postoperative survival rate and disease free survival rate were analyzed by the Kaplan-Meier method, and differences in survival rates were assessed with the log-rank test. A Cox proportional-hazard model was used for the multivariate analyses. Differences were considered significant when $\mathrm{P}<0.05$. Each statistical analysis was performed using the SPSS II software program, version11.0.1J for Windows (SPSS, Inc., Chicago, IL).

\section{Results}

Characteristics of histone modifications. Representative immunostaining results for the three histones are shown in Fig. 1. Only nuclear staining for the three histones was regarded as positive, and cases were scored for each mark using a modified $\mathrm{H}$-score. Histograms showing the staining intensity and distribution of $\mathrm{H}$-scores plotted against the number of cases are shown in Fig. 1.

The expression of histone markers correlates with the clinicopathological factors. The expression scores of the histone modifications were categorized as low or high according to whether they were $<150$ or $\geq 150$. The relationship between the expression levels of three histone modifications and the patient age, gender, tumor size, histological type, depth of invasion, location of lymph node metastasis and adjuvant chemotherapy after first operation, were assessed. The H3K4me2 status was positively correlated with the tumor histological type of the liver metastasis. The H3K9ac status was also positively correlated with the tumor histological type. However, the H3K9me2 status was found to only significantly correlate with gender (Table I). 

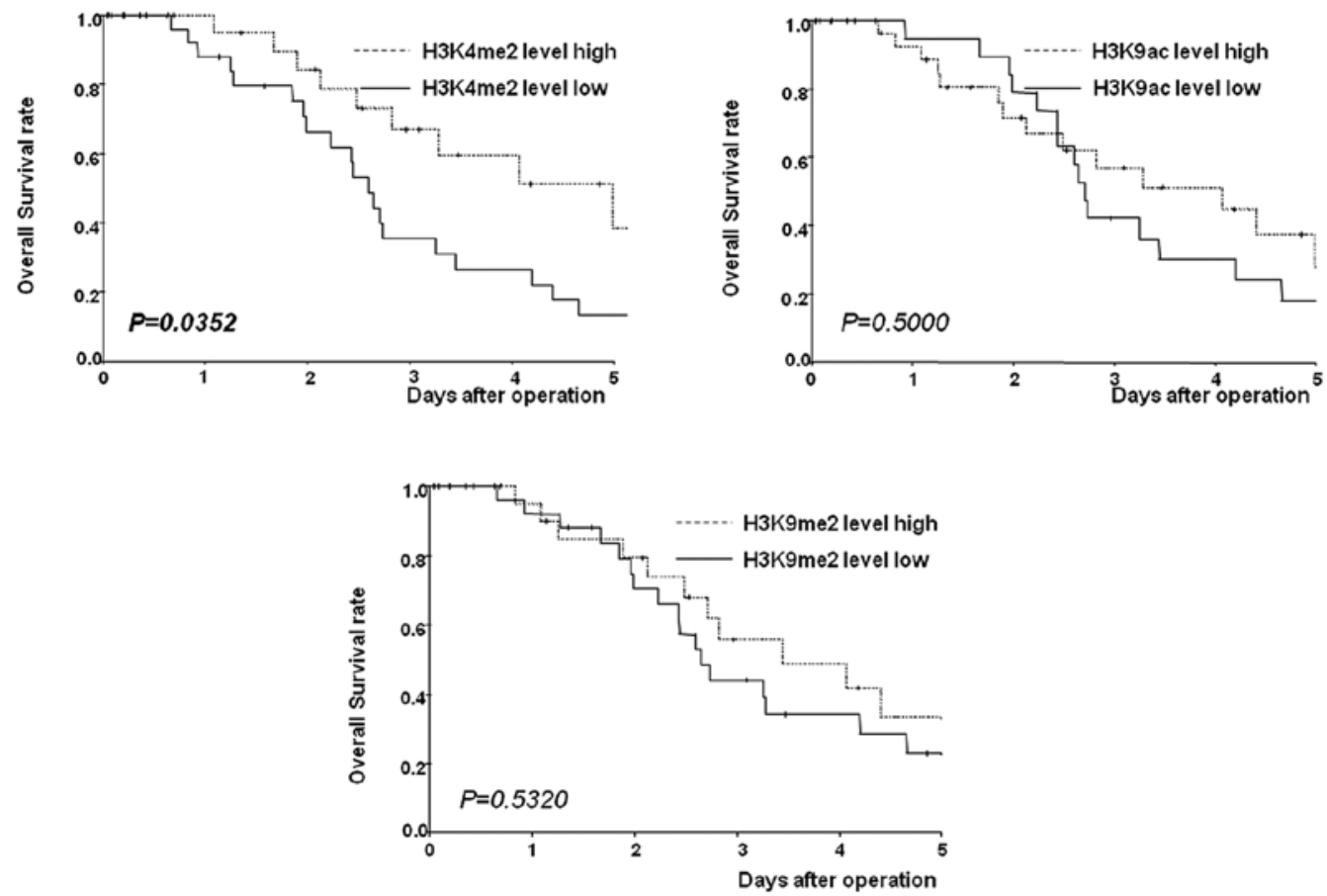

Figure 2. The Kaplan-Meier survival curves with the log-rank test for 54 patients after resection of the liver metastasis. A comparison of the overall survival based on liver metastases between the groups with high $\mathrm{H} 3 \mathrm{~K} 4 \mathrm{me} 2, \mathrm{H} 3 \mathrm{~K} 9 \mathrm{me} 2$ and $\mathrm{H} 3 \mathrm{~K} 9 \mathrm{ac}$ expression and low expression, respectively. The group with high expression of $\mathrm{H} 3 \mathrm{~K} 4 \mathrm{me} 2$ in liver metastases showed significantly better survival than the group with low expression $(\mathrm{P}=0.0352)$.
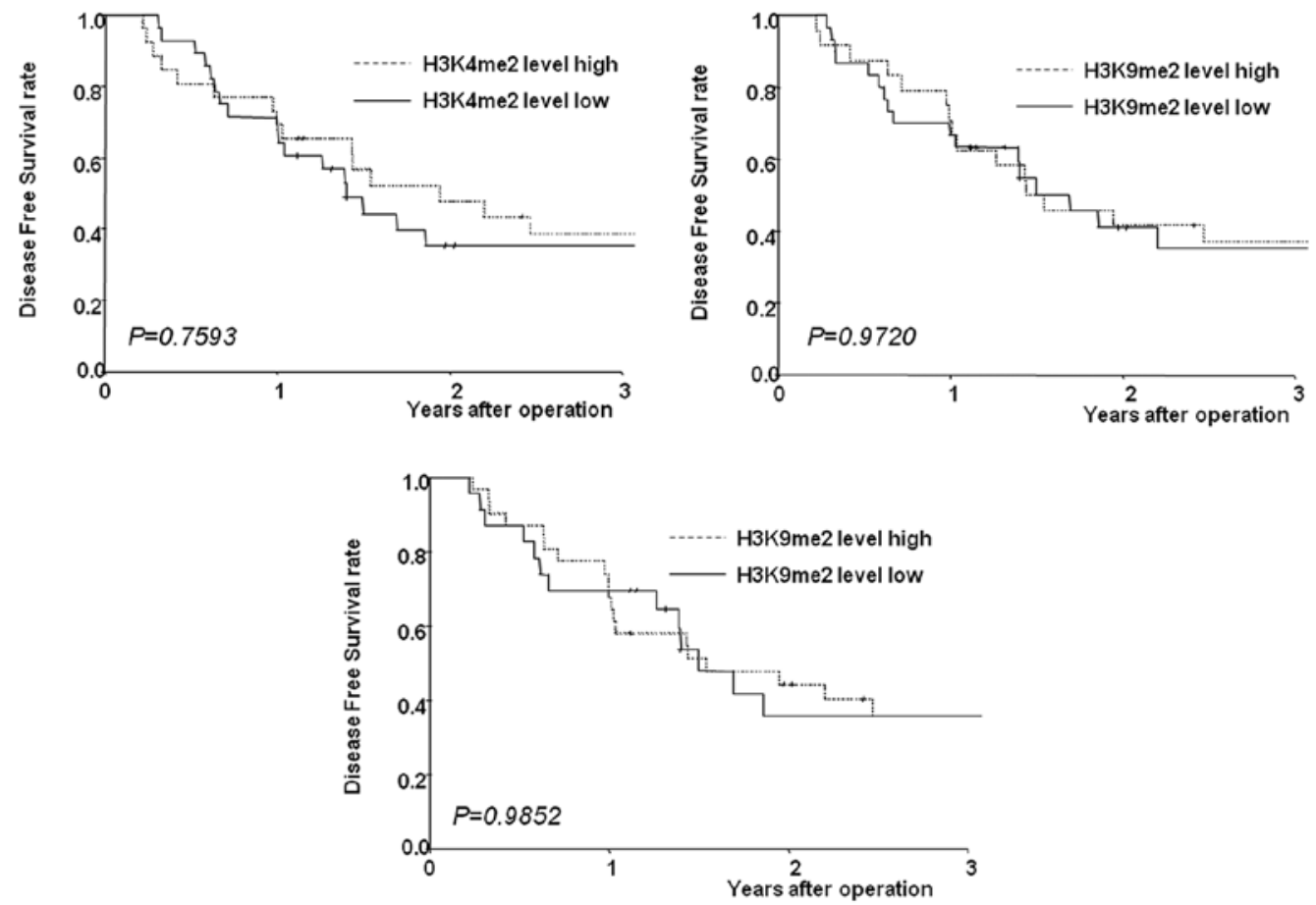

Figure 3. The Kaplan-Meier disease free survival curves with the log-rank test for 54 patients after resection of the liver metastasis. A comparison of the overall survival based on liver metastases between the groups with high H3K4me2, H3K9me2 and H3K9ac expression and low expression of each of these factors. There were no significant differences between the histone levels.

Relationships between histone markers and patient outcomes. With regard to the modification patterns, the group with high expression of $\mathrm{H} 3 \mathrm{~K} 4 \mathrm{me} 2$ showed significantly better survival from the day of liver resection than those with a low expression level $(\mathrm{P}=0.0352)$. The group with high expression of
H3K9me2 and H3K9ac showed a better survival than those with low expression, but the difference was not significant (H3K9me2, $\mathrm{P}=0.5320$; H3K9ac, $\mathrm{P}=0.5000$, Fig. 2). The disease free survival between the day of liver resection and the second recurrence did not significantly correlate with any 
Table II. The results of a multivariate analysis of the clinicopathological factors for overall survival.

\begin{tabular}{|c|c|c|c|c|}
\hline Variables/categories & $\mathrm{n}$ & $\begin{array}{c}\text { Hazard } \\
\text { ratio }\end{array}$ & $95 \% \mathrm{CI}^{\mathrm{b}}$ & P-value \\
\hline \multicolumn{5}{|l|}{ Size $(\mathrm{cm})$} \\
\hline$<5$ & 31 & 1 & & \\
\hline$\geq 5$ & 23 & 1.919 & $0.922-3.922$ & $0.081^{\mathrm{c}}$ \\
\hline \multicolumn{5}{|l|}{ Histological type $^{\mathrm{a}}$} \\
\hline Well/Moderate & 50 & 1 & & \\
\hline Poor/Mucinous & 4 & 1.342 & $0.335-5.370$ & $0.678^{c}$ \\
\hline \multicolumn{5}{|l|}{ Depth of invasion } \\
\hline T1-T3 & 26 & 1 & & \\
\hline $\mathrm{T} 4$ & 28 & 1.305 & $0.551-3.091$ & $0.545^{\mathrm{c}}$ \\
\hline \multicolumn{5}{|l|}{ Location } \\
\hline Colon & 32 & 1 & & \\
\hline Rectum & 22 & 1.166 & $0.488-2.787$ & $0.73^{\mathrm{c}}$ \\
\hline \multicolumn{5}{|c|}{ Lymph node metastasis } \\
\hline Absent & 16 & 1 & & \\
\hline Present & 38 & 0.51 & $0.206-1.262$ & $0.145^{\mathrm{c}}$ \\
\hline \multicolumn{5}{|l|}{ Preoperative CEA } \\
\hline Absent & 32 & 1 & & \\
\hline Present & 21 & 1.012 & $0.370-2.774$ & $0.981^{\mathrm{c}}$ \\
\hline \multicolumn{5}{|l|}{ Preoperative CA19-9 } \\
\hline Absent & 36 & 1 & & \\
\hline Present & 16 & 2.396 & $1.024-5.604$ & $0.044^{\mathrm{c}}$ \\
\hline \multicolumn{5}{|c|}{ Adjuvant chemotherapy } \\
\hline Absent & 24 & 1 & & \\
\hline Present & 30 & 1.928 & $0.852-4.363$ & $0.115^{\mathrm{c}}$ \\
\hline \multicolumn{5}{|l|}{ H3K4me 2 expression } \\
\hline Low & 28 & 1 & & \\
\hline High & 26 & 0.338 & $0.146-0.783$ & $0.011^{c}$ \\
\hline
\end{tabular}

${ }^{a}$ Well, well differentiated; Moderate, moderately differentiated; Poor, poorly differentiated. ${ }^{\mathrm{b}} \mathrm{CI}$, confidence interval. ${ }^{\mathrm{c}} \mathrm{Cox}$ proportional hazard regression. Bold indicates values that were statistically significant $(<0.05)$.

histone modification pattern (Fig. 3). The median follow-up period was 907 days.

Prognostic factors for colorectal cancer. On a multivariate Cox regression analysis including tumor size, histological type, depth of invasion, lymph node metastasis, preoperative (the first colorectal resection) CEA, CA19-9 and a lower level of $\mathrm{H} 3 \mathrm{~K} 4 \mathrm{me} 2$, H3K4me2 expression and preoperative CA19-9 was an independent predictor of overall survival in patients with CRC (H3K4me2, P=0.011; CA19-9, P=0.044, Table II).

\section{Discussion}

Epigenetic alterations, such as DNA methylation and histone modification, play important roles in carcinogenesis by controlling gene activity and nuclear structural design $(21,22)$.
Recent studies have suggested that the global patterns of histone modifications can be used to predict patient outcomes for several cancers. The aim of this study was to determine the prognostic significance of histone modification in metachronous liver metastases by using an immunohistochemical analysis.

We first examined the relationship between histone modifications and clinicopathological features. In gastric carcinoma, Park et al (9) reported that cases with more H3K9ac-positive cells tended to be poorly differentiated adenocarcinomas. In esophageal squamous cell carcinoma, I et al (13) reported that the global levels of H3K9Ac and H3K9me2 in well-differentiated cases showed a tendency to be higher than those in moderately or poorly differentiated cases, but the difference in these levels were not found to be statistically significant. Our present study demonstrated that a high $\mathrm{H} 3 \mathrm{~K} 4 \mathrm{me} 2$ level in the liver metastasis tended to be present in subjects with poorly differentiated adenocarcinomas, and that a positive $\mathrm{H} 3 \mathrm{~K} 9 \mathrm{ac}$ status also tended to be associated with poorly differentiated adenocarcinomas.

We then examined the relationship between three histone modification levels and the outcomes of CRC with metachronous liver metastasis. Seligson et al (5) previously reported that prostate carcinoma patients with low cellular levels of $\mathrm{H} 3 \mathrm{~K} 4 \mathrm{me} 2$ had a poorer prognosis, with a significantly increased risk of tumor recurrence compared with patients with higher levels of this modification. In lung cancer patients, a high $\mathrm{H} 3 \mathrm{~K} 4 \mathrm{me} 2$ level ( $\geq 85 \%$ of tumor cells) was associated with a significantly better survival of stage I patients with large-cell or squamous cell carcinomas. In addition, low H3K9ac levels ( $<68 \%$ of tumor cells) were also associated with a better survival of stage I patients. In the case of pancreatic carcinoma, low cellular levels of $\mathrm{H} 3 \mathrm{~K} 4 \mathrm{me} 2$ or $\mathrm{H} 3 \mathrm{~K} 9 \mathrm{me} 2$ were both significant and independent predictors of poor survival in the univariate and multivariate models (11). In our study, a high level of $\mathrm{H} 3 \mathrm{~K} 4 \mathrm{me} 2$ modification in liver metastases was associated with a better overall survival than a low level of this histone modification in patients with CRC. According to a univariate Cox regression analysis, a lower level of H3K4me2 modification in the liver metastases was a significant independent predictor of overall survival in these patients.

Histone modifications and DNA methylation seem to play an important role in regulating transcription and other nuclear processes. Previous reports have shown the relationship between histone modifications and DNA methylation in cancer cells. For example, promoter CpG-island hypermethylation in cancer cells has been reported to be associated with a particular combination of histone markers, for example, deacetylation of histones $\mathrm{H} 3$ and $\mathrm{H} 4$, loss of $\mathrm{H} 3 \mathrm{~K} 4$ trimethylation, and gain of H3K9 methylation and H3K27 trimethylation (23). In addition, Dnmt3L interacts with unmethylated H3K4 through its $\mathrm{N}$-terminus and with Dnmt3a through its C-terminus, thus linking the DNA methylation machinery to the modification state of histone tails (24). However, while the biochemical mechanism underlying histone demethylation has been deciphered, it is still not clear how methyl groups are removed from DNA (25).

Recently, several groups have reported these epigenomic modifications to predict the clinical outcomes in human cancers, and $\mathrm{H} 3 \mathrm{~K} 4$ and $\mathrm{H} 3 \mathrm{~K} 9$ modifications are important 
in the epigenetic silencing of tumor suppressor genes. Of interest, there is evidence that epigenomic profiles can predict the responses of cancer to chemotherapy, at least in pancreatic carcinoma. One report showed that the histone levels were predictive of survival specifically for patients with nodenegative cancer or for those receiving adjuvant fluorouracil, but not gemcitabine (11). The impact of histone levels on $\mathrm{CRC}$ is not clear. If the histone modification proves to be a useful biomarker in the other cancers, then the existence of a ready-made target treatment would be invaluable for future chemotherapy.

Recent and ongoing comprehensive cancer genome studies have been identifying many gene alterations involved in histone modifications (26). Most strikingly, high-resolution SNP genotyping of medulloblastoma identified many previously unknown recurrent gene amplifications and homozygous deletions, and those events converged on genes controlling histone lysine methylation (27). We speculate that the H3K4 or H3K9 hypomethylation status may be caused by multiple genetic alterations of histone methylation modifiers, which may trigger global histone lysine modifications, rather than modification on specific gene regions of limited number, and as a whole, this is associated with the higher malignant behavior of CRC.

In conclusion, our results suggest that the pattern of histone modifications in liver metastasis as detected by immunohistochemistry can be successfully used as an independent prognostic factor for metachronous liver metastasis of colorectal cancer.

\section{References}

1. Weitz J, Koch M, Debus J, Hohler T, Galle PR and Buchler MW: Colorectal cancer. Lancet 365: 153-165, 2005.

2. Homsi J and Garrett CR: Hepatic arterial infusion of chemotherapy for hepatic metastases from colorectal cancer. Cancer Control 13: 42-47, 2006.

3. Yasui W, Sentani K, Motoshita J and Nakayama H: Molecular pathobiology of gastric cancer. Scand J Surg 95: 225-231, 2006.

4. Kurdistani SK: Histone modifications as markers of cancer prognosis: a cellular view. Br J Cancer 97: 1-5, 2007.

5. Seligson DB, Horvath S, Shi T, et al: Global histone modification patterns predict risk of prostate cancer recurrence. Nature 435 : 1262-1266, 2005.

6. Seligson DB, Horvath S, McBrian MA, et al: Global levels of histone modifications predict prognosis in different cancers. Am J Pathol 174: 1619-1628, 2009.

7. Barlesi F, Giaccone G, Gallegos-Ruiz MI, et al: Global histone modifications predict prognosis of resected non-small cell lung cancer. J Clin Oncol 25: 4358-4364, 2007.

8. Van Den Broeck A, Brambilla E, Moro-Sibilot D, et al: Loss of histone H4K20 trimethylation occurs in preneoplasia and influences prognosis of non-small cell lung cancer. Clin Cancer Res 14: 7237-7245, 2008.
9. Park YS, Jin MY, Kim YJ, Yook JH, Kim BS and Jang SJ: The global histone modification pattern correlates with cancer recurrence and overall survival in gastric adenocarcinoma. Ann Surg Oncol 15: 1968-1976, 2008.

10. Wei Y, Xia W, Zhang Z, et al: Loss of trimethylation at lysine 27 of histone $\mathrm{H} 3$ is a predictor of poor outcome in breast, ovarian, and pancreatic cancers. Mol Carcinog 47: 701-706, 2008.

11. Manuyakorn A, Paulus R, Farrell J, et al: Cellular histone modification patterns predict prognosis and treatment response in resectable pancreatic adenocarcinoma: results from RTOG 9704. J Clin Oncol 28: 1358-1365, 2010.

12. Toh Y, Yamamoto M, Endo K, et al: Histone H4 acetylation and histone deacetylase 1 expression in esophageal squamous cell carcinoma. Oncol Rep 10: 333-338, 2003.

13. I H, Ko E, Kim Y, et al: Association of global levels of histone modifications with recurrence-free survival in stage IIB and III esophageal squamous cell carcinomas. Cancer Epidemiol Biomarkers Prev 19: 566-573, 2010.

14. Elsheikh SE, Green AR, Rakha EA, et al: Global histone modifications in breast cancer correlate with tumor phenotypes, prognostic factors, and patient outcome. Cancer Res 69: 3802-3809, 2009.

15. Kondo Y, Shen L and Issa JP: Critical role of histone methylation in tumor suppressor gene silencing in colorectal cancer. Mol Cell Biol 23: 206-215, 2003.

16. Heard E, Rougeulle C, Arnaud D, Avner P, Allis CD and Spector DL: Methylation of histone H3 at Lys-9 is an early mark on the $\mathrm{X}$ chromosome during $\mathrm{X}$ inactivation. Cell 107: 727-738, 2001.

17. Mermoud JE, Popova B, Peters AH, Jenuwein $\mathrm{T}$ and Brockdorff N: Histone $\mathrm{H} 3$ lysine 9 methylation occurs rapidly at the onset of random X chromosome inactivation. Curr Biol 12: 247-251, 2002.

18. Nguyen CT, Weisenberger DJ, Velicescu M, et al: Histone $\mathrm{H} 3$-lysine 9 methylation is associated with aberrant gene silencing in cancer cells and is rapidly reversed by 5 -aza-2'-deoxycytidine. Cancer Res 62: 6456-6461, 2002.

19. Schotta G, Lachner M, Sarma K, et al: A silencing pathway to induce $\mathrm{H} 3-\mathrm{K} 9$ and $\mathrm{H} 4-\mathrm{K} 20$ trimethylation at constitutive heterochromatin. Genes Dev 18: 1251-1262, 2004

20. McCarty KS Jr, Miller LS, Cox EB, Konrath J and McCarty KS Sr: Estrogen receptor analyses. Correlation of biochemical and immunohistochemical methods using monoclonal antireceptor antibodies. Arch Pathol Lab Med 109: 716-721, 1985.

21. Jones PA and Baylin SB: The fundamental role of epigenetic events in cancer. Nat Rev Genet 3: 415-428, 2002.

22. Hake SB, Xiao A and Allis CD: Linking the epigenetic 'language' of covalent histone modifications to cancer. Br J Cancer 90: 761-769, 2004.

23. Esteller M: Cancer epigenomics: DNA methylomes and histonemodification maps. Nat Rev Genet 8: 286-298, 2007.

24. Ooi SK, Qiu C, Bernstein E, et al: DNMT3L connects unmethylated lysine 4 of histone $\mathrm{H} 3$ to de novo methylation of DNA. Nature 448: 714-717, 2007.

25. Cedar $\mathrm{H}$ and Bergman Y: Linking DNA methylation and histone modification: patterns and paradigms. Nat Rev Genet 10: 295-304, 2009.

26. Shah MY and Licht JD: DNMT3A mutations in acute myeloid leukemia. Nat Genet 43: 289-290, 2011.

27. Northcott PA, Nakahara Y, Wu X, et al: Multiple recurrent genetic events converge on control of histone lysine methylation in medulloblastoma. Nat Genet 41: 465-472, 2009. 